Para enlazar con este artículo / To link to this article:

http://dx.doi.org/10.14198/fem.2017.30.10

Para citar este artículo / To cite this article:

Peña Rodríguez, Francisco José. «El teatro de Ana Merino: una propuesta para el siglo XXI». En Eva García-Ferrón y Cristina Ros-Berenguer (coords.), Dramaturgia femenina actual. De 1986 a 2016. Feminismo/s, 30 (diciembre 2017): 193-207, DOI: 10.14198/fem.2017.30.10

\title{
EL TEATRO DE ANA MERINO: UNA PROPUESTA PARA EL SIGLO XXI
}

\author{
ANA MERINO'S THEATER: \\ A PROPOSAL FOR THE $21^{\text {ST }}$ CENTURY
}

\author{
Francisco José PeÑa RodRíGUEZ \\ IES Miguel de Cervantes (Fuenteálamo, Albacete) \\ Universidad Autónoma de Madrid \\ franciscojosepr@yahoo.es \\ orcid.org/0000-0002-1381-1238
}

\section{Resumen}

En este trabajo se analiza, desde una lectura múltiple (textual, lingüística, social), el teatro de la poeta madrileña Ana Merino (Madrid, 1971) como una propuesta dramatúrgica para el siglo XXI. En una etapa de crisis del teatro actual, el análisis de sus piezas teatrales recogido en este estudio muestra su obra como una aportación novedosa en el contexto del teatro femenino español actual.

Palabras clave: España, teatro, poetas, dramaturgas, propuesta teatral.

\begin{abstract}
This article discusses from a multiple reading (textual, linguistic, social) the theatre of the Spanish poet Ana Merino (Madrid, 1971) as a new dramaturgy proposal for 21st century. In context of crisis in the current theatre, the analysis of her theatre's plays collected in this article shows her theatre as a singular contribution in context of the current Spanish female theatre.
\end{abstract}

Keywords: Spain, theatre, poetess, playwrights, theatrical proposal. 



\section{INTRODUCCIÓN}

En la dramaturgia española de los últimos veinte años hallamos una serie de características propias del teatro que acentúan ciertos aspectos críticos: una constante argumentación a favor de una continua crisis escénica posterior a la Transición (1976-1982) y la aparición de nuevos nombres que revitalizan la escena, singularmente comediógrafas nacidas en el tardofranquismo e incorporadas al teatro con el cambio de siglo. En el primero de los casos el profesor José-Carlos Mainer incide en que la crisis teatral es «crónica»-más allá de media docena de propuestas-, quizás por «la omnipresencia de la subvención pública» (210); en el segundo, la escritura de una serie de obras singulares, de la mano de dramaturgas a cuya cabeza el propio Mainer sitúa a Paloma Pedrero y Angélica Lidell (210), aporta una prolongación de la tradición teatral española con dosis de realismo y leve experimentación. En este contexto, otros nombres más allá de las consagradísimas Ana Diosdado o Lourdes Ortiz añaden novedosas visiones teatrales que no se ciñen exclusivamente al teatro convencional que se ha venido desarrollando hasta los años noventa del siglo XX.

El estudio de dramaturgias particulares, basado en el análisis de todos los aspectos intervinientes en la escritura dramática y puesta en escena de la pieza, se nos hace necesario. Así, el propio libreto; el lenguaje, desde el punto de vista denotativo o connotativo, pero también desde su uso social en la obra en relación con el público; la ficcionalidad del universo teatral; la configuración global de la obra como un todo literario; su escenicidad y, además, su valor social. En definitiva, todos los ámbitos formales y estilísticos de la misma se reconocen necesarios para analizar estéticas singulares que puedan añadirse a la tradición teatral de nuestros días.

La exégesis de la obra teatral de Ana Merino permite entender su dramaturgia como una propuesta estética válida y en consonancia con el teatro actual desarrollado por mujeres, tal como se mostrará en adelante. Además, la proyección futura de su obra -todavía en ciernes- permite consolidar las tesis defendidas por críticos que han adelantado en estudios precedentes la obra ya clásica de autoras de nuestros días, como Angélica Lidell e Itziar Pascual, tanto en obras monográficas como en ensayos de conjunto que el lector verá 
citados y encontrará anotados en el apartado bibliográfico. En ese sentido, este trabajo pretende, desde el análisis teatral de Ana Merino, incorporarla al canon de dramaturgas actuales, toda vez que la autora tiene ya tras de sí un bagaje poético singularmente relevante desde mediados de los años noventa.

Así pues, al permanente debate -no siempre clarificador-acerca de la crisis del teatro español y a las originales propuestas teatrales de las nuevas dramaturgas, unidas a los nombres de autoras consagradas como Paloma Pedrero o M. ${ }^{a}$ Manuela Reina, entre otras, se unen nuevas aportaciones como la de Ana Merino (Madrid, 1971), quien se ha sumado a la escritura dramática con tres obras de significativa temática social y, al mismo tiempo, con un marcado propósito experimental desde el punto de vista estético y temático.

Amor: muy frágil (2012), Las decepciones (2014) y La redención (2016) implican, inicialmente, un compromiso social a partir de una profunda mirada hacia problemas y debates actuales, como las relaciones entre personas del mismo sexo, el amor y sus fórmulas en el siglo XXI o la idea de destrucción del planeta a causa de la contaminación y los efectos del calentamiento global. Además, esos temas y la prospección en otros secundarios, la experimentación formal basada en estructuras de cuatro actos (Amor: muy frágil), seis (La redención) o siete (Las decepciones) conllevan una apuesta escenográfica singular, en consonancia con las propuestas innovadoras y vanguardistas del teatro español materializadas desde principios del siglo XX. La propia Merino reconoce que «lo que buscaba era expresar mi universo» ${ }^{1}$ (Peña/Merino 2017).

Hasta bien entrado el último cuarto del siglo XX las propuestas teatrales de la mano de dramaturgas no pasaban de más allá de algún breve epígrafe en los manuales canónicos de la literatura actual, o de esporádicas reseñas en la prensa; análogamente, la singular historia del teatro español -por otra parte excelente en matices, ideas y nombres- se ha centrado en una inmensa mayoría de autores, entre los que se abrieron paso inicialmente nombres como los de María Martínez Sierra (María de la O Lejárraga, 1874-1974), Pilar MillánAstray (1879-1949) o Concha Méndez (1898-1986) a inicios del siglo pasado. No obstante, nuevas visiones de la literatura española actual y, sobre todo, un reconocimiento del papel literario de las comediógrafas en el teatro actual permiten explicar el teatro de los últimos veinticinco años desde autoras como Lourdes Ortiz y Carmen Resino hasta Gracia Morales o la propia Ana Merino. Desde 1980 el teatro español se enfrentó a circunstancias políticas y sociales que, por una parte, facilitaron un replanteamiento de temas, fórmulas y

1. Cita recogida a través de la correspondencia electrónica mantenida con la autora el 30 de octubre de 2017. 
representaciones y, por otra, incorporaron nuevos nombres, entre los cuales se encuentran los ya clásicos de la dramaturgia española actual. De ese modo, con el final de la dictadura los textos hasta ese momento prohibidos o mutilados por la censura pudieron representarse ( $E l$ público, de Federico García Lorca, o El Adefesio, de Rafael Alberti); en consonancia, las propuestas más vanguardistas y revolucionarias, frente al teatro convencional del franquismo (Alfonso Paso, Joaquín Calvo Sotelo), tenían cabida en las salas habituales y no únicamente en los círculos teatrales independientes, casi siempre ligados a estudiantes universitarios. Es en ese momento cuando se da a conocer Lourdes Ortiz con Las murallas de Jericó, obra que había obtenido el Premio Aguilar del año 1978. A raíz de la victoria socialista de 1982, las instituciones públicas recuperan la iniciativa del fomento teatral más allá de las salas de Madrid y Barcelona, de tal modo que diputaciones provinciales y ayuntamientos, conjuntamente con comunidades autónomas, restablecieron espacios y reivindicaron parcialmente nombres silenciados por el franquismo: basta citar el caso de la rehabilitación del Teatro Circo de Albacete (2002) dedicado además a la ópera -género escasamente puesto en escena en esa ciudad-o de la reedición de obras de autoras como la mencionada Concha Méndez, María Teresa León (La libertad en el tejado) o Carlota O'Neill (1905-1990), a quien destaca especialmente el profesor Romera Castillo en un reciente trabajo (228-231).

Por otro lado, Virtudes Serrano sitúa en el año 1983 «el renacer de la dramaturgia femenina en España» (2004, 562-563), explicitando que además de mostrar su trabajo varias autoras, vieron la luz tres significativas obras teatrales: Un olor a ámbar, de Concha Romero; Ulises no vuelve, de Carmen Resino (Premio Lope de Vega, 1974) y El navegante, de María Manuela Reina, que recibió el Premio SGAE. Sea como fuere, en el último tramo del siglo pasado la dramaturgia femenina cobra singular importancia y aparece ligada a la renovación teatral que la Transición y la consolidación democrática posterior permitió en nuestro país, sobre todo porque a la altura de 1990 aún «la presencia de nombres femeninos, tanto españoles como extranjeros, en la nómina de los autores resulta ser bastante exigua. Las mujeres representan sólo el 10,92\% de los dramaturgos que se encuentran en la cartelera madrileña» (Lo Porto 373). Más tarde, el teatro del siglo XXI permitirá verificar la convivencia de varias generaciones de dramaturgas en la publicación de obras y estrenos teatrales.

Como fenómeno análogo a la poesía actual escrita por mujeres o a la narrativa desligada del denominado best seller, el teatro del siglo XXI adquiere un valor temático e interpretativo que, en gran medida, se debe a propuestas de mujeres. Así, a los nombres que despuntaron en los ochenta (Lidia Falcón, Lourdes Ortiz, Helena Pimenta, Paloma Pedrero) se suman las nuevas 
promociones de autoras que, si bien nacen en los últimos años del franquismo, se educan ya en la democracia y toman conciencia social y literaria en los años de consolidación de unas libertades que implican el conocimiento y la formación intelectual más allá de la universidad, además de vivir ligadas a experiencias viajeras en interdisciplinariedad artística o literaria. En definitiva, autoras como Natalia Menéndez, Angélica Lidell, Itziar Pascual, Ana Merino o Gracia Morales desarrollan su textualización teatral en el siglo XXI.

\section{ANA MERINO: ENTRE LA POESÍA Y EL TEATRO}

Ana Merino Norberto nació en Madrid el 25 de junio de 1971 y es hija del escritor y académico de la RAE José María Merino. Se licenció en Historia Moderna y Contemporánea por la Universidad Autónoma de Madrid (1995) y, más tarde, realizó el Doctorado en Estudios Culturales y Transatlánticos (especializándose en Teoría del Cómic) por la Universidad de Pittsburgh (2001). A raíz de la obtención de una Beca Erasmus, a mediados de la década de 1990 residió en Groningen (Holanda), ciudad en la que surgieron algunas de las composiciones de su primer poemario, Preparativos para un viaje, Premio Adonáis de 1994.

La década pasada decide establecerse en Estados Unidos, desempeñando la docencia universitaria en la Appalachian State University (Carolina del Norte, 2001-2003), Dartmouth College (New Hampshire, 2004-2009) y, actualmente, en la University of Iowa, en donde dirige además el MFA de Escritura Creativa.

Merino se dio a conocer en la literatura a partir de la obtención del mencionado Premio Adonáis de 1994. Así, el galardonado Preparativos para un viaje vio la luz en 1995, al que siguieron Los días gemelos (1997) y La voz de los relojes (2000). En 2003 Juego de niños obtuvo el Premio Fray Luis de León de Poesía, concedido por la Diputación Provincial de Cuenca. A esos títulos hay que añadir Compañera de celda (2006), Curación (Visor 2010) y Hagamos caso al tigre (2010). Su poesía ha sido traducida al inglés y al alemán.

Nuestra autora ha alcanzado gran repercusión por sus estudios sobre el cómic, fruto de los cuales son los ensayos El cómic hispánico (2003) y Chris Ware: la secuencia circular (2005). Es colaboradora habitual de la revista española Leer, columnista del diario El País y ha sido galardonada con el Premio Diario de Avisos por sus artículos sobre el cómic.

En el plano teatral, la incorporación de Ana Merino a la escena se produce en la segunda década del siglo XXI. Debuta en 2012 con el estreno de Amor: muy frágil en el Theater Stok de Zúrich bajo su propia dirección, llevando más adelante la obra a teatros de Biel y San Galo (San Gallen), también en Suiza, en el otoño de ese año. Más adelante publica Las decepciones (2014) y La redención (2016); esta última se representó igualmente bajo la dirección de 
la propia Merino, en el Teatro de la Universidad de Iowa en 2017. A su pluma se debe, asimismo, la pieza breve Escenas alrededor de la leyenda de Bernardo del Carpio (2013).

Por añadidura, nuestra autora se ha introducido en el terreno narrativo con la novela juvenil El hombre de los dos corazones (2009) y algunos relatos publicados en obras colectivas.

Sobre el quehacer teatral, desde un punto de vista formal, José Luis Alonso de Santos resalta las pautas clásicas, formales y técnicas en La escritura dramática (1998) que, en esencia, se cumplen a la hora de analizar el teatro de Ana Merino. No obstante, la propuesta teatral de la autora permite establecer una coexistencia entre el planteamiento clásico de la obra, esencialmente en cuanto a la construcción del personaje, sus características y circunstancias, y la recreación de la atmósfera espacial en la que transcurre la acción dramática. Por ello, se puede afirmar que su propuesta dramática combina el teatro convencional con una evidente experimentación escénica -sobre todo- que va más allá del tratamiento temático que se evidencia en sus tres obras iniciales: el amor, el engaño, el sexo, la amistad, la culpa y lo social, entre otros que se matizarán más adelante.

A propósito de su actividad creadora, Ana Merino en 2006 explicaba en una entrevista sobre su formación académica en la Universidad Autónoma de Madrid que:

El trayecto a Cantoblanco, en tren o autobús, es perfecto para las distancias cortas de los cuentos o los poemas. Pero muchos estudiantes no saben lo que significa el placer de la lectura, el placer de abstraerse con una historia o un poema que tienes que descifrar, se conforman poniéndose unos cascos con música y no hacen esfuerzos. Leer significa un esfuerzo y como son «chicos audiovisuales» no saben construir espacios fijos de atención. Esto yo lo veo en España, en México o en Estados Unidos. (Peña 2006, 9)

La idea recurrente del tren como fuente inspiradora se traslada a la creación teatral, de ahí que la autora reconozca la concepción y escritura de Las decepciones en un tren entre San Galo y Zúrich, por los días en que en la primera de estas ciudades se representaba Amor: muy frágil. De este modo, ella misma explica que:

Las decepciones se fueron fraguando en el tren de San Gallen a Zúrich durante todo el otoño de 2012. Viajaba al menos tres veces por semana para ir a los ensayos de Amor: muy frágil, la que fue mi primera obra de teatro que yo misma dirigí y monté con un grupo de actores hispano-suizos. La aventura de ese montaje me hizo adicta a sus sensaciones y me llenó de energía para escribir esta otra pieza. $(2014,9)$ 
Es evidente que esta anécdota no es más que una parte mínima de su labor creadora, a pesar de que la propia dramaturga reconozca que también La redención fue concebida «mientras volaba de Zúrich a Edimburgo a comienzos de abril de 2013» $(2016,7)$. En realidad, la construcción de la obra teatral de Merino en todo su sentido queda explicada, habitualmente, en los prólogos de sus obras, como también hacía, por ejemplo, Enrique Jardiel Poncela.

El proceso ideológico que lleva a textualizar la obra literaria requiere de un proceder formal-estilístico que, como ha estudiado Manuel Pérez Jiménez (2005), configura la obra teatral desde lo ficcional a la escenicidad. En ese sentido, la propia Ana Merino explica la génesis de sus obras desde aspectos sociales y humanos que derivan en materia teatral procedente de la observación o vivencia de lo cotidiano. Así pues, La redención nace de la reflexión personal acerca de que «algún día tendremos que darnos cuenta de que la contaminación es una losa que nos hunde. Es un aura ominosa que está en el aire, el mar y la tierra. Llevamos más de medio siglo contaminando sin parar» $(2016,10)$; una reflexión social que vuelve la vista, como referentes que servirán para configurar la atmósfera distópica de la pieza, hacia Chernóbil y Fukushima y las catástrofes medioambientales que se dieron allí en 1986 y 2011, respectivamente. Esa distopía nace, incluso, de una situación personal en el aeropuerto de Ámsterdam que incidió en el proceso de escritura de la obra teatral.

Por añadidura, la mudanza personal desde Nueva Inglaterra (Darmouth College) al Medio Oeste norteamericano (Iowa), el desencanto y el cansancio que la burocracia universitaria produce en la docente-autora-poeta conlleva una apuesta por el teatro: de esa introspección personal a unas notas de diario y de la imagen difusa de un personaje a la escritura de Amor: muy frágil (Merino 2012, 14-15). Paralelamente, las conversaciones en los ensayos con los actores de esa obra derivaron en la idea central de Las decepciones.

En tanto que dramaturga que, además, ha dirigido los montajes escénicos de sus obras, Merino pasa de lo ideológico a lo formal, a la plasmación de lo espacio-temporal o a la dramatización de personajes y acciones con una ágil discursividad -discursividad alternada-, en consonancia con las líneas dominantes en la dramaturgia actual. Por otra parte, la elección del teatro no es aleatoria, ya que, como ella misma confesará, «el teatro es una apuesta mucho más interesante que la novela súper-ventas» (Peña/Merino 2017).

\section{EL TEATRO DE ANA MERINO}

La trayectoria teatral de Ana Merino es aún reciente, lo cual no le impide aportar una mirada de modernidad dramática -propia de las autoras actuales- en 
consonancia con otras propuestas españolas o americanas como la de la argentina Lola Arias (Buenos Aires, 1976).

Así pues, la concepción dramática de la autora se mueve entre el teatro de síntesis (M. ${ }^{a}$ José Ragué-Arias, Pilar Pombo) y las novísimas propuestas (Yolanda García Serrano, Sara Molina), cuyos comienzos podemos situar a finales de los años noventa e inicios de la década pasada (Prieto de Paula y Langa, 263-275). Asimismo, la tradición clásica -con sus singulares dosis de experimentación- se da cita en el teatro de Ana Merino, ya que, desde mi punto de vista, Benito Pérez Galdós y Antonio Buero Vallejo comparecen tras las temáticas de Amor: muy frágil o La redención. Parece evidente que la pasión lectora de la comediógrafa está presente en el trasfondo de la elaboración de personajes y tramas; no en vano, ella misma confesaba en 2006 su amplio bagaje de lecturas clásicas:

Son muchas las lecturas. Desde los clásicos españoles del Siglo de Oro hasta la generación del 27 al completo, pasando por los ingleses, latinoamericanos, franceses... He tenido la suerte de crecer en una casa con una biblioteca inmensa donde los libros de poesía se leían constantemente. (Peña 2006, 9)

En Amor: muy frágil ${ }^{2}$ el planteamiento temático parte de que dos amigos, Jorge y Matías, comienzan una relación amorosa inserta en un triángulo pasional, ya que el primero de ellos está casado con Ada, con la que se resiste a romper sentimentalmente. Como consecuencia de esos amores casi clandestinos surgen, a su vez, emociones y sentimientos encontrados (el engaño, la amistad, la dependencia afectiva, los hijos...) que llevan a Matías a desarrollar unos intensos celos. La autora verbaliza así un tema candente en España en los años iniciales del siglo XXI, el de las parejas homosexuales -recordemos que en 2005 se produjo la aprobación del matrimonio entre parejas del mismo sexo-. Un debate también abierto en Estados Unidos, país de residencia de la escritora, que aumenta por tanto el valor social del planteamiento teatral.

Ana Merino recupera aquí el tema del ménage à trois de la tradición literaria occidental, pero desde un punto de vista radicalmente diferente y rompiendo el esquema convencional de la mujer atrapada entre dos amores masculinos: en esta obra aparece una pareja masculina en el centro de la relación y la mujer de uno de ellos (Ada) resulta el factor que impide el normal desarrollo de la experiencia amorosa. Este nuevo triángulo amoroso tiene su razón de ser en una sociedad moderna, con planteamientos vitales novedosos pero, igual que

2. La pieza se estrenó a finales de 2012 en el ya mencionado Teatro Stok de Zúrich, bajo la dirección de la propia Merino y con un elenco de actores formado por Alberto Ruano, Sandra Zellweger, Rainer Jutzi, Sandra Vilas, Mireya Sánchez, Sonia Díaz y Carolina Flores. 
en otras obras de similar planteamiento temático, aparece detrás una sociedad con sus convencionalismos- que finalmente impedirá la libre elección de Jorge y Matías. Por extensión, esa atmósfera social, representada principalmente por la familia y los hijos, incide en la imposibilidad de ruptura entre Jorge y Ada, beneficiando así la cohesión familiar. Los elementos espacio-temporales justifican del mismo modo los sentimientos de insatisfacción y frustración que desarrolla el libreto teatral.

Paralelamente, esta obra recuerda, en mi opinión, a La de San Quintín, de Benito Pérez Galdós (1894), cuyo leit motiv es igualmente un triángulo amoroso, cuyo arriesgado planteamiento en la época contó en su estreno con notable polémica. No obstante, Ana Merino matiza que «la verdad es que he escrito de manera muy libre, pero he tenido presente la tradición española del teatro. A Lope, a Cervantes y a Calderón, pero también el teatro de Galdós o Buero. Creo que me he empapado a través de sus obras de esa pulsión literaria que reivindico» (Peña/Merino 2017).

En La redención ${ }^{3}$ un grupo de trabajadores en el tratamiento de residuos (Isabel, Ada, Nicolás, Rodrigo y Jaime) acude a una planta cercana al mar, en un lugar difuso, para tratar de procesar el material almacenado; una vez allí, se recrea una atmósfera cercana a la ciencia ficción (distopía). En ese panorama desalentador se suscitarán sentimientos encontrados entre los personajes, dando lugar a emociones divergentes como el pesimismo, la soledad, la pulsión amorosa o la sensación de abuso de poder. La obra enuncia análogamente algunos de los problemas sociales más acuciantes de nuestro tiempo: la incomunicación en la era de las nuevas tecnologías, las nuevas relaciones laborales que frustran y empobrecen al trabajador -surgidas en la época de crisis económica y social en la que se escribe la pieza teatral- y, al mismo tiempo, plantea a través de los personajes (Ada, Isabel, Rodrigo) estereotipos de ciudadanos competentes cuya psicología se ve transformada por la acción teatral, en función de las circunstancias límite y contradictorias que se producen con el transcurso de los actos que componen la pieza.

A pesar de la singularidad de esta pieza teatral, La Fundación (1974), de Antonio Buero Vallejo, se percibe, de nuevo desde mi punto de vista, tras la línea argumental de esta obra: una «redención» con la que sueñan los protagonistas. En esta obra de Merino las precisas intervenciones de Ada y Rodrigo, sobre todo, irán mostrando la sensación de búsqueda de una salida a

3. Esta obra fue estrenada en mayo de 2017 en Iowa, codirigida por Ana Merino y Taylor Claman. El elenco de actores, procedentes en su mayoría de la University of Iowa, estuvo formado por Karla Álvarez, Beatriz O. Gallardo, Eloy Barragán, Jim Evans, Horacio Olivo y Valeria Amado. 
la inmovilidad de las vidas de los personajes, previa introspección en su pasado y en sus propias pulsiones y sentimientos.

Las decepciones resulta una obra marcada, en diferentes momentos, por una atmósfera metafísica. Está protagonizada por un profesor cincuentón y tres de sus alumnos: Marta, Sara y Mauro. Afectados todos ellos por un atentado crucial en sus vidas, ese hecho desencadena la pluralidad de enfoques y puntos de vista humanos que, del mismo modo que los acerca como amigos, también los aleja. En este drama Merino acude a un tema actual y muy presente en la sociedad occidental, el del terrorismo (11-S, 11-M), para desarrollar la escritura dramática de la obra. La comediógrafa se introduce incluso en las nuevas fórmulas de relación entre profesores y alumnos, surgidas de la evolución de los métodos de enseñanza universitarios occidentales. También aparece el tema de la educación como fórmula de reflexión social o la proyección del mundo universitario como referente desde el que analizar la sociedad en la que viven los protagonistas y plantear soluciones a los problemas sociales. El tema de la educación como superador de las dificultades de la sociedad está muy presente en toda la obra y la ideología de la autora:

Creo firmemente que la educación es la llave fundamental que redime el mundo. Y dentro de ese proceso son clave los maestros y profesores porque son los que nos ayudan a madurar y a crecer [...] Por eso me dedico a la educación, porque creo que la única forma de cambiar el mundo es educando a la gente; enseñarles a pensar y a que aprendan a valorar el mundo que les rodea... a desarrollar su propio criterio ideológico e intelectual respetando siempre a los demás. Pero la educación empieza en las escuelas cuando somos niños y nos enseñan a leer, a valorar la literatura y a imaginar. (Peña 2006, 9)

En líneas generales, el teatro de Ana Merino está concebido con fórmulas «muy directas y expresivas» (Alvar, Mainer y Navarro, 660), propias de la poética de su obra previa. Así, la obra teatral de la autora madrileña está muy ligada a los problemas sociales de su tiempo pero, además, experimenta mediante la construcción de personajes complejos, desde el punto de vista psicológico, cuyos traumas y experiencias personales anteriores a la acción dramática salen a la luz en el contexto del argumento principal. Son, de igual modo, personajes que evolucionan al ritmo de la obra teatral, sin demasiadas acotaciones que especifiquen sus características físicas o psicológicas y que, por extensión, quedan estéticamente a merced de la visión del espectador, en virtud del desarrollo dramático de cada pieza.

Paralelamente, cada obra teatral implica una mirada hacia la sociedad, con una intención didáctica -quizás- que no siempre tiene una lectura lineal debido a la complejidad de los personajes, más allá de la urdimbre textual. En ese sentido, la prospección en las interioridades de Ada o los protagonistas 
masculinos de La redención aportan una visión mucho más compleja de la idea central: la salvación del universo de su propia autodestrucción medioambiental. Si por un lado Jaime llega a decir que «hay esperanza. Los índices de radiación han bajado» (38), por otro, Rodrigo deja de lado ese optimismo para exteriorizar que:

Mi yo anterior retornará. Los rincones de mi existencia consciente pueden volver a mí (suspiros). Todos los días me despierto buscando la clave de mi ser anterior y solo noto cuchilladas clavándose en mi espalda. Puñales de olvido que me atan al espanto de los malos presentimientos. (58)

Es preciso mencionar, en el mismo sentido, que el reflejo de la realidad lingüística de nuestros días es evidente, recogiendo un lenguaje estándar y cotidiano propio de la condición de clase media de casi todos los protagonistas de la dramaturgia de Merino. Esa representación verbal, que implica un entendimiento e identificación del lector-espectador con el personaje, es evidente en Amor: muy frágil o La redención. Desde otro punto de vista, en Las decepciones la autora se permite modular ese lenguaje, ya que el hecho de que tres de sus protagonistas (Marta, Sara y Mauro) sean estudiantes facilita la diversidad verbal en aras de la verosimilitud.

En relación con esta última obra, el cambio de registro entre el profesor y los alumnos es mínimamente perceptible: por un lado el docente mantiene unos parlamentos en consonancia con su posición intelectual y, por otro, los alumnos se permiten expresiones algo más coloquiales o cotidianas, especialmente Sara. Esta protagonista incorpora en sus intervenciones expresiones como «tabletas digitales», «navego por la red», «terminaba enganchando las bragas y los leotardos» (39); o, más adelante, otras como "profe», «jugoso blog» (50) o "ganazas» (67), incluso se permitirá la ironía: «Hay algún que otro chorizo que tiene esas ocurrencias, muy culto sí, pero a base de mangonear...» (61).

Sara es, desde mi punto de vista, el personaje más redondo de la citada obra, como considero que Matías y Ada lo son en Amor: muy frágil y La redención, respectivamente. La estudiante de Las decepciones es, pues, fiel reflejo de alumnos universitarios de hoy -pese al impacto que en ella causa el atentado y sus secuelas posteriores- $y$, como se viene especificando, sirve a la autora para marcar la diferencia, desde el punto de vista del lenguaje teatral, con el resto de personajes en el teatro de Ana Merino. De ese modo, Sara verbaliza parlamentos cargados no solo de cotidianidad, sino también -como se ha vistode humor e ironía: «Parece un pavo real. Qué manera de inflarse (con ironía). Qué satisfacción. Parece que levita, ¿no?» (64). 
Por lo que se refiere a la concepción general de su teatro, Ana Merino no busca la complejidad formal, estética, en cada obra teatral; tampoco hay, en su aún corta trayectoria como comediógrafa, ningún tipo de alarde estilístico o vanguardismo que la aleje de la conexión con el público. Es más, la proyección de toda suerte de sentimientos y emociones -como se ha escrito- busca la comunicación directa con el público que, en cierto modo, se siente identificado o disiente de los planteamientos sobre el engaño, el amor, las relaciones interpersonales, el medio ambiente, el egoísmo, la culpa y un sinfín más de temas y subtemas que subyacen en la confusión vital de los protagonistas.

Simultáneamente, el compromiso social -como hemos visto- no llega necesariamente a un compromiso político, sino a una actitud o mirada crítica que arroje una lectura personal de los problemas colectivos en la actualidad. No hay en sus obras y planteamientos textuales -por el momento- una lectura política, aunque sí un «compromiso con la humanidad» a través de la escritura dramática.

Acerca de la diversidad en actos de su obra, de cómo los tres actos convencionales no le son útiles y los modifica, supeditándolos al discurso teatral, comenta la autora:

De pronto los tres actos se me quedaban cortos. Me gustó mucho adentrarme en la voz literaria de los personajes y eso hace que los actos tengan otra dinámica [...] En Amor: muy frágil lo llevaba a dos casas y pasaba en cuatro actos, en Las decepciones todo se desarrollaba en 7 actos y La redención lo llevo a seis actos. Me gusta que los personajes se muevan en espacios diferentes y marcar las diferencias entre esos espacios, con actos donde hay oscuridad y cambio de escenario. Creo que eso limpia la escena y permite que el espectador respire. Reivindico un teatro de pulsión literaria, ese aspecto me parece importante. Quiero retornar al teatro de actores que interpretan vida y pensamiento. Creo que en los últimos años se ha primado el ritmo de textos breves en cada intervención donde los actores dicen ocurrencias y no se profundiza. Mi reivindicación es la pulsión existencial literaria como expresión teatral [...] Creo en la fuerza del teatro como espacio de reflexión social. (Peña/Merino 2017)

Es por ello que la lectura de cada obra, la comunicación directa con el público, el mensaje claro que transmite cada planteamiento tiene una fuerte dosis de didactismo.

\section{CONCLUSIÓN}

Toda obra abierta -como la de Ana Merino y otras autoras de nuestros díasimplica una conclusión también abierta de ideas acerca de una obra literaria y de su valor en el contexto literario del momento histórico. Por lo que se refiere a este trabajo, con él se ha expuesto una visión muy general de la dramaturgia 
y estética de la autora madrileña en una nueva faceta de su trayectoria literaria; una interpretación textual de sus obras -a excepción de la pieza breve titulada Escenas alrededor de la leyenda de Bernardo del Carpio- que, pese a su edición en España y la puesta en escena de dos de ellas en Suiza y Estados Unidos, aún deben subir a las tablas en nuestro país ${ }^{4}$.

En este estudio se ha mostrado el teatro de Merino como una propuesta que se cimenta en tres aspectos singulares. En primer lugar, en una verbalización que, con un lenguaje estándar cargado de ironía, gira hacia lo coloquial en diversos personajes (Las decepciones) y en torno a temas profundamente sociales, así como con un punto de vista personal que los pone en consonancia con el público. En segundo lugar, una configuración de personajes complejos cuyas emociones y sentimientos no necesariamente se subordinan a la acción principal de la obra. Y, por último, una innovación en cuanto al número de actos, los cuales, como se ha dicho, relacionan a la dramaturga con los experimentos teatrales de inicios del siglo XX. En este último aspecto es reseñable que ninguna de sus obras se ciña a los tres actos convencionales, pese a una extensión del libreto muy similar a la de las obras clásicas 5 .

En cuanto al teatro de nuestros días, parece evidente que su revitalización, innovación y, sobre todo, apuesta escénica se debe en gran medida a las propuestas que vienen de la mano de autoras que tomaron las tablas a principios de nuestro siglo y que arriesgan teatralmente en un momento en el que, parafraseando al profesor Mainer, la crisis crónica del teatro nos permitiría tener esperanza.

\section{REFERENCIAS BIBLIOGRÁFICAS}

Alonso de Santos, José Luis. La escritura dramática. Madrid: Castalia, 1998.

Alvar, Carlos, José-Carlos Mainer y Rosa Navarro. Breve historia de la literatura española. Madrid: Alianza, 2014.

Checa Puerta, Julio. «Mujeres y teatro en la escena actual: Angélica Lidell (1966) e Itziar Pascual (1967)». ALEC 36.2 (2011): 85-112.

García-Pascual, Raquel (ed.). Dramaturgas españolas en la escena actual. Madrid: Castalia, 2011.

4. El académico José María Merino reconoció al autor de este trabajo que «quizás el motivo por el cual aún no se han estrenado en España sea que Ana vive en Estados Unidos y un montaje requiere una presencia constante y de tiempo, sobre todo en los ensayos y en el montaje». (Entrevista en León, 19 de octubre de 2017).

5. Es preciso señalar que Lourdes Ortiz, Carmen Resino, Paloma Pedrero, Lluisa Cünillé o Laila Ripoll, entre otras, tienen piezas de un único acto. 
Lo Porto, Valeria Maria Rita. «Puesta en escena de obras de dramaturgas en la cartelera de ABC de Madrid (1990)». Signa 21 (2012): 369-393.

Mainer, José-Carlos. Historia mínima de la literatura española. Madrid: Turner/El Colegio de México, 2014.

Merino, Ana. Amor: muy frágil. Madrid: Reino de Cordelia, 2012.

Merino, Ana. Las decepciones. México: Consejo Nacional para la Cultura y las Artes, 2014.

Merino, Ana. La redención. Madrid: Reino de Cordelia, 2016.

Nieva de la Paz, Pilar. «Las autoras teatrales españolas frente al público y la crítica (1918-1936)». Actas del XI Congreso de la Asociación Internacional de Hispanistas. Irvine, 1992, 129-139.

Pedraza Jiménez, Felipe B., y Milagros Rodríguez Cáceres. Manual de literatura española. XIV Posguerra: dramaturgos y ensayistas. Pamplona: Cénlit, 1995.

Pedrero, Paloma. Pájaros en la cabeza. Teatro a partir del siglo XXI. Ed. Virtudes Serrano. Madrid: Cátedra, 2013.

Peña Rodríguez, Francisco José. «La obra de Ana Merino: hacia la poesía del siglo XXI». Género y géneros I: Escritura y escritoras iberoamericanas. Ed. Ángeles Encinar, Eva Löfquist y Carmen Valcárcel. Volumen 1. Madrid: Universidad Autónoma de Madrid, 2006, 373-383.

Peña Rodríguez, Francisco José. «La educación es la llave que redime el mundo». Encanto Blanco 37 (octubre 2006): 8-9.

Pérez Galdós, Benito. La de San Quintín. Electra. Ed. Luis F. Díaz Larios. Madrid: Cátedra, 2002.

Pérez Jiménez, Manuel. «Panorama formal-estilístico de la dramaturgia femenina actual». Dramaturgias femeninas en la segunda mitad del siglo XX: espacio y tiempo: actas del XIV Seminario Internacional del Centro de Investigación de Semiótica Literaria, Teatral y Nuevas Tecnologías. Coord. José Romera Castillo. Madrid: UNED, 2005, 509-524.

Prieto de Paula, Ángel L., y Mar Langa Pizarro. Manual de Literatura Española Actual. Madrid: Castalia, 2007.

Romera Castillo, José. Teatro español entre dos siglos a examen. Madrid: Verbum, 2011.

Serrano, Virtudes. «Política, teatro y sociedad: temas de la última dramaturgia española». Monteagudo 2 (1997): 75-92.

Serrano, Virtudes. «Dramaturgia femenina fin de siglo. Estado de la cuestión». Arbor CLXXVII (Marzo-Abril 2004): 561-572. 